the tendons, that which by its anatomical arrangement offers the largest share of resistauce, - the tendo Achillis, for example,and complete the cure by mechanical elongation of remaining tissues. But if, in cases of average severity, you perceive that the anterior and posterior tibial are very tense, the fibres of the patient robust, and unlikely to yield to mechanical treatment, you will determine to divide these also. In numerous instances the flexor muscles of the toes and the plantar fascia are conjointly affected, and you consequently effect division of those within your reach, the flexor longus pollicis, plantar fascia, or even the abductor pollicis. After every section many tissues remain for elongation by mechanical treatment. The same mechanical apparatus is required subsequently as previously to operation.

The operative treatment of severe $\mathbf{T}$. varus in youths and adults may be advantageously divided into two stages. Owing to the slowness of restoration in extreme cases (as at fig. 32), the treatment often occupying six months, it is proper to divide, in the lirst instance, the tendons and other structures which adduct the foot, and devote attention to its eversion so as to reduce it to the condition of $T$. equinus, and subsequently to sever the tendo Achillis and depress the heel. Your object will be, in the first instance, to reduce a complicated deformity to a more simple form. A common splint, bandaged on the outer side of the limb, often proves the best mechanism for this purpose. The depression of the internal edge of the foot can be better effected by the action of the perpendicular spring (fig. 34) than by any other contrivance with which I am acquainted. By this means the most severe congenital $T$. varus, in patients even of thirty years of age, may be entirely removed. The after-development of muscles and acquisition of strength of limb may be facilitated by the general measures which I have so often enumerated whilst speaking of other deformities.

\section{PHYSIOLOGY AND PATHOLOGY} OF THE URINE.

BY

George E. Day, M.A., L.M., Cantab., Physician to the Finsbury Dispensary, \&c.

(Continued from vol.ii., 1842-3, p. 609.)

In my last communication $I$ stated that $I$ should commence this paper with a brief notice of the results deduced from my own experiments. The whole of the daily urine of a man aged thirty, of good constitution, and living very temperately, was collected, and a portion of it was analysed upon six alternate days in March, and upon four alternate days in June. The average quantity of urine excreted in twenty-four hours was, during the continuance of these experiments, about thirty-eight ounces, the maximum being forty-three and the minimum thirty-four ounces.

The mean specific gravity was 1022.5. The mean results of the analyses are expressed in the following table :-*

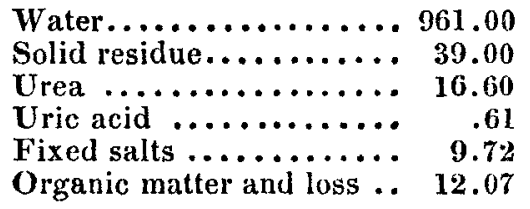

In all cases it is the best plan to analyse a portion of the mixed urine of twenty-four hours; as, however, there are many difficulties, both in private and dispensary practice, in preserving the urine in this manner, I usually content myself with a specimen of the urine first passed upon waking, as being less likely to be influenced by disturbing causes than that passed during the day.

Urea.-According to Becquerel the quan. tity of urea passed in twenty four hours amounts in man to about two hundred and seventy grains, and in woman to about two hundred and forty grains.

Macgregor stafes the average quantity at 428.5 grains, Christison at 510 grains, and Brande at 1320 grains. In eight experiments made upon himself, Lehmans found that (while living on his ordinary diet) the maximuin quantity of urea was 602 grains, the minimum 427 grains, and the average 500 grains. 'The following observations of Lecann are of sufficient value to find a place here, although some of them need farther confirmation. From a long and careful series of analyses he came to the couclu. sions, -

1. That the quantity of urea voided in twenty-four hours is very different in different individuals. One man, for instance, passed 509.3 grains, and another only 185.3 grains daily.

2. That in the same individual the quantity of urea voided in twenty-four hours does not vary cousiderably.

Thus, in A it only varied from 365.8 to 483.4 grains, in twelve experiments.

$B$, it only varied from 373.1 to 481.9 grains, in twelve experiments.

$C$, it only varied from 357.4 to 462.6 grains, in seven experiments.

* Not having a very fine balance I cannot positively rouch for the accuracy of the second decimal place ; I believe, however, that the figures in the table are, in every case, correct.

t Brande's lectures on Organic Chemistry, reported in the "Medical Times." The quantity is so incredible that we conclude that it must be an error of printing, probably for 320. 
$D$, it only varied from 419.2 to 466.8 grains, in four exprriments.

$E$, it only varied from 426.6 to 501.0 grains, in six experiments.

3. That when the aqueous portion of the urine is increased the quantity of urea which is excreted does not undergo a corresponding change.

4. That no certain inferences can be drawn from the specific gravity, regarding the quantity of urea.

For purposes of clinical observation we usually see Prout's method of ascertaining the proportion of urea arlopted in this country:-" For practical purposes an excess of urea may be shown by putting a little of the urine in a watch-glass, and adding to it carefully about an equal quantity of pure nitric acid, in such a manner that the acid shall subside to the bottom of the glass. The mixture must be kept as cool as possible, and if, under these circumstances, a crystallised deposit be found, an excess of urea is indicated. The degree of excess may be inferred near enough for practical purposes by the length of time which elapses before crystallisation takes place, which may be from a few minutes to two or three hours."-(Pront on the Nature and Treatment of Stomach and Urinary Diseases ; Introduction, p. 73, note.)

Rayer objects to Prout's method, on the grounds that the results are uncertain, and I have myself occasionally observed that when similar quantities of urine and nitric acid have been placed in similar watchglasses, and subjected to similar influences, there bas been a discrepancy in the circumstances attending the crystallisation.

Rayer's method is to place a couple of drops of urine on a piece of flat glass, and add to them a minute drop of nitric acid. Upon placing the slip of glass under the microscope the quantity of crystals of nitrate of urea, and the rapidity with which they are formed, will indicate, with tolerable correctness to the practised eye, the circumstance of there being either an excess or a diminution in the proportion of the urea.

Several theories have recently been advanced with regard to the state in which urea exists in the urine. We shall briefly notice a few of those which, from the high character of their promulgators, are the most deserving of our attention. Persoz considers that almost all the substances found in the urine are the products of oxidation (as, for instance, lactic, uric, oxalic, and other acids), and that the functions of the kidney are to bring about the oxidation of the substances contained in the blood. Whether this oxidation is dependent upon the saturated state of the oxygenised blood that passes through the renal arteries, or whether it is dependent upon the decomposition of water, Persoz cannot decide; he is, however, inclined to adopt the latter hypothesis, on account of the presence of ammonia, whose constitution must remain a mystery if we reject the idea of its hydrogen being generated by the decomposition of water.

" The day will probably soon arrive," he observes, "when we shall be able to demonstrate the presence of compounds of cyano. gen in the blood, and the oxygenation of the cyanogen will lead to the formation of urea, for a cyanate in contact with a watery solution of an ammoniacal salt leads directly to the formation of this substauce." He contends that it is only the constituents of the urea, not the urea itself, that exist ready formed in the urine, and that urea itseif is formed from these constituents, by the action of certain influences, especially that of heat acting upon some of the principles of this animal fluid.

In confirmation of this view he addnces the following experiments: Upon exposing urine to a degree of cold varying from $0^{\circ}$ to $10^{\circ} \mathrm{Fah}$. it freezes from without inwards, leaving, however, in the centre, an uncrystallisable syrup, upon which nitric acid pro. duces no apparent effect. If, however, we carefully warm this syrup, taking care not to increase the heat so as to cause any concentration, we can really obtain crystals of nitrate of urea.

Morrin has published a paper upon this subject in the 61st volume of the "Annales de Chimie et de Physique." Without entering into a detail of the experiments upon which his views are founded, it is suficient for our purpose to state that he came to the following conclusions:-First, that urea does not exist as a free substance in the urine; and, secondly, that we find it combined with chlorine, or mnriatic acid, in the proportion of six or eight atoms of urea with one of chlorine; thirdly, that, on treating: urine with oxalic acid, we obtain a silt whose base is not urea, but a substance which is composed of one atom of nitrogen and two of hydrogen, and to which Morrin applies the name urile ;* fourthly, that it is this urile, and not urea, which exists in the urine, and with which the chlorine is com. bined; fifthly, that when acted upon by nitric acid urea is produced. Morrin was led to form these views regarding the combiuation of urile with chlorine by observing that coarse, unpurified urea (that, namely, which is oblained by treating a concentrated syrup of urine with alcohol, and allowing it to crystalise) throws down, with an aqueous solution of nitrate of silver, a chloride which exceeds in quantity the tixed chlorides of the urine. The excess of chloride of silver could not be attributed to the presence

* The urile of Morrin is neither more or less than amidogen. It must not be confounded with the uril or urilic acid $\left(\mathbf{C}_{8} \quad \mathbf{N}_{3}\right.$ $\mathrm{O}_{4}$ ) of Woehler and Liebig. 
of muriate of ammonia in the substance experimented wil $h$, because, upon the addition of sulphate of copper, and of caustic potash, to the aqueous solution, the green tint was permanent, and no ammoniacal odour was evolved, contrary to what would have occurred if any muriate of ammonia had been present in the solution of urea.

Much of his evidence rests upon quantitative analyses, which it is unnecessary for us here to revert to. The next researches upon this subject, worthy of notice, are those of Cap and Henry. The conclusions at which they arrived (see the original essay in vol. 25 of the "Journal de Pharmacie") were,-

First. That the urea does not exist in a free state in the urine.

Secondly. That it acts the part of a base, and is found in the human species principally in combination with lactic acid; in the ruminants in combination with hippuric acid; and in serpents and birds with uric acid, or at least with a peculiar acid (the urile of Liebig) which is the radical of uric acid.

Thirdly. That the natural lactate of urea obtained from the human urine is identical with the same salt prepared artificially.

The process by which they obtained the lactate of urea (as described in their second essay, published in June, 1841), is here given sumewhat in detail, in order to enable any of my readers, who take an interest in the question, to follow their method with ex actness.

They evaporated fresh humau urine to about five-six ths of its bulk at a temperature not exceeding $248^{\circ}$ Fah., and obtained, on cooling, a bright, brown, and very acid liquor, which was carefully filtered, in order to deprive it of the deposit formed during concentration. The liquid was then evaporated at a gentle heat to the consistence of a syrup, and subsequently placed in vacuo over strong sulphuric acid until it became nearly dry. The residue was placed in a stoppered glass bottle, and there was added to it a mixture of two parts of sulphuric ether and one part of rectified alcobol, in the proportion of ten or twelve times the weight of the mixture to the residue. The bottle was frequently shaken, and after a few days the liquid (which was of an amber colour) was poured off. Upon adding to this liquid a slight excess of carbonate of lime, of zinc, or of baryta, or bicarbonate of potash, and shaking the bottle, effervescence occurs, and there are produced lactate and phosphate of lime, zinc, baryta, or potash, by the saturation of the free lactic and phosphoric acids which are contained in the urine. Upon again filtering the liquid ethereal portion, and exposing it to a gentle heat, there were produced very fine crystals of lactate of urea, perfectly similar to those artificially prepared. These crystals appeared as long, transparent, hexagonal prisms, had a sharpish taste, and were volatile at a moderate heat. They were very soluble in water, alcohol, or alcoholised ether, but less so in sulphnric ether. They exhibited very powerful hy. grometric qualities (in this respect differing much from urea), dissolving entirely when exposed to the air, -and forming a brightcoloured solution, which, when gently heated, again furnished crystals.

In order to ascertain the state of combination of the lactic acid with the urea the following experiments were made; the crystals of the supposed lactate of urea were divided into three equal portions, and marked $A$, B, C.

A. These crystals were dissolved in pure water, and slightly treated with bydrated oxide of zinc. The mixture was evaporated to dryness, and treated with sulphuric ether, which dissolved the urea, and subsequently yielded it in crystals, which were not hy grometric; the residue, on being treated with hot distilled water, filtered and evaporated, yielded white, acicular, styptic crystals of lactate of zinc.

B. Somewhat similarly acted upon by a solution of bary ta.

C. From this portion, upon the addition of a salt of lime, a soluble salt was obtained, which crystallised on cooling, and possessed all the ordinary characters of lac. tate of lime.

Cap and Henry themselves confess that the lactate of urea is not very easily obtained, and they assign three causes for this difficulty. They consider it due, first, to the excess of lactic acid in the urine; second, to the great solubility of the lactate of urea, and the high degree of concentration required to obtain it in a crystalline form; and, thirdly, to the extreme volatility of the salt, which requires that the concentration should be carried on with great care and attention.

From one thousand parts of urea, they obtained eighteen parts of lactate of urea, which corresponds very nearly to nine parts of urea.*

Whether the urea in the human urine does really exist as a lactate is still undecided. Lecanu, Gregory, Pelouze, Garrod, and other chemists, have carefully followed the steps laid down by Cap and Henry, but have not arrived at similar conclusions. Lecanu, to whom we are indebted for several interesting essays upon subjects connected with the urine, has not only endeavoured to point out the incorrectness of the views of Cap and Henry, but has gone further, and investigated the theories propounded by Persoz and Morrin. For tbe purpose of testing the accuracy of Persoz's views, he exposed the

* Lactate of urea consists of 49.61 per cent. of urea, and 50.39 per cent. of lactic acid. 
mixed urine of several individuals in perfect bealth, to a cold of about $14^{\circ} \mathrm{Fah}$., for the space of from eighteen to twenty-four hours. The frozen mass was broken up, and placed in a glass funnel, over a piece of cotton, which was placed there in order to catch any of the urine that might remain fluid; upon expressing this fluid from the cotton, and adding nitric acid, pearly lamellar crystals of nitrate of urea were immediately formed. Similarly, upon the addition of oxalic acid, the granular appearance of oxalate of urea was very soon seen. From these, and numerous similar experiments; from the fact that in numerous cases a deposit of nitrate of urea is immediately produced upon the addition of an equal quantity of nitric acid to urine in a watch-glass; and, lastly, from the fact of the nitrate of urea being formed in exactly the same man. ner, whether the urine is evaporated by the air-pump and sulphuric acıd, or by heat, we must be led to agree with Lecanu, in considering that there must have been some fallacy in Persoz's experiments.

The results of another series of experiments lead us to conclusions that the existence of urile, as described by Morrin, cannot be admitted, since the substance obtained in accordance with his directions, contains muriate of ammonia, whose presence at once explans both its appearance during distillation, and the precipitated chloride, which is obtained upon the addition of nitrate of silver. Moreover, urea may be obtained without having recourse to any reagents ca. pable of decomposing the pretended chloricie of urile, and converting it into urea. 'The views of Woehler, Dumas, and Berzelius, with regard to the purely chemical nature of urea, will be referred to in our section upon the chemistry of that substance. We shall notice Liebig's views on the subject, when speaking of uric acid, from which he supposes it to be derived by a purely chemical process.

Uric Acid.-The quantity of uric acid excreted by different individuals, seems to vary greatly. Becquerel states that, on an average, men pass about 7.6 grains, and women 8.8 grains of uric acid daily. The proportion in one thousand parts may be seen in the analyses at page 609 of the last volume of The LanceT.

The following analyses are reduced from those of Lecanu. For brevity we intend $\mathbf{M}$ to signify the maximum quantity of uric acid excreted in twenty-four houl's, and $\mu$ the minimum, and $A x$ the average quantity, deduced from $x$ analyses; and $\mathbf{R} y$ the ratio, deduced from $y$ analyses. $A, B, C, I, K$, are the cases referred to under the same initials in my last paper ; $\mathbf{D} \mathbf{E} \mathbf{F}$ indicate middle aged men of good constitution; $J$ and $L$ refer to females, aged 43 and 19 respectively; the former being of a bilious, the latter of a lymphatic temperament.
Grains.

Grains.

A $\{M=24.31 \ldots \ldots \mu=9.75$

$\left\{A_{12}=15.38 \ldots \ldots R_{12}=1.071\right.$

B $M^{12}=23.71 \ldots \ldots \mu^{12}=7.9$

$A_{12}=15.41 \ldots \ldots R_{12}=1.037$

C $M^{12}=21.82 \ldots \ldots \mu \mu^{2}=8.9$

$A_{8}=17.28 \ldots \ldots \mathbb{R}_{8}=1.175$

D $A_{1}=23.35 \ldots \ldots R_{1}=.704$

E $\left\{M^{1}=6.99 \ldots \ldots \mu \mu=2.36\right.$

$A_{6}=4.66 \ldots \ldots R_{6}=1.766$

$\mathrm{F}\left\{\mathrm{M}^{6}=13.89 \ldots \ldots \mu \mu^{\prime}=2.84\right.$

$\left\{A_{10}=6.20 \ldots \ldots R_{10}=0.454\right.$

I $\left\{\mathrm{M}^{10}=10.79 \ldots \ldots \mu=5.89\right.$

$\left\{\mathbf{A}_{8}=7.28 \ldots \ldots \mathbf{R}_{7}=0.331\right.$

J $\mathbf{M}=7.1 \ldots \ldots \mu \mu=0.76$

$\left\{\mathbf{A}_{3}=6.98 \ldots \ldots \mathbf{R}_{3}=0.76\right.$

K $M^{3}=11.25 \ldots \ldots \mu^{3}=6.350$

$A_{4}=9.11 \ldots \ldots R_{4}=0.635$

L $\left\{\mathrm{M}^{4}=10.50 \ldots \ldots \mu^{2}=4.21\right.$

$A_{4}=6.67 \ldots \ldots R_{4}=0.59$

From this series of experiments Lecanu came to the conclusion that, in health, the quautity of uric acid excreted in twenty four hours, may vary, at least, from upwards of 24 grains, to less than 2.5 grains; and that, possibly, the range might have been even more extended if the experiments had been more numerous; that healthy urine contains from $\frac{1}{352}$ to $\frac{1}{5000}$ th of its weight of uric acid; and that the uric acid voided bears no constant ratio to the quantity of urine. He also concludes that, in the same individual, uric acid is secreted in nearly equal quantities in equal times, but that in different individuals the secretions of uric acid may vary very much during equal times.

Lehmann made an examination of his own urine, while in perfect health, and living on his ordinary mixed diet, for thirteen days consecutively. The following numbers express the mean of his results. The specific gravity was 1022.3 ; the daily quantity of urine rather more than $\mathbf{3 3}$ ounces; the daily quantity of uric acid very nearly 18 grains; and the proportion in one thousand parts, 1.089.

According to Duvernoy, the average quan. tity of uric acid in health is about 1 grain in 12 ounces, or about 3 grains in twenty-four hours; and from Lr. 'Thomson's analysis, given in my last paper, we should be led to conceive (from the data there furnisbed to us) that the daily secretion would be under 5 grains. We may probably revert to these discrepancies when speaking of the influence of food and climate upon the production of urea and uric acid.

We shall not offer any remarks, in the present paper, upon the state in which the uric acid exists in the urine; upon the means by which it is held in solution; or upon the nature of those deposits which are due to an excess of this acid in the urine, but shall proceed to a more detailed notice of the in. organic matters than we have yet done. 
Inorganic Mlatters. - I have already (in and produces a little torrent of fire, forming my first paper) fully explained the method, a continuous column, 6 inches high, for which I consider the best, for the estimation of about twenty minutes. It is extinguished the fixed salts collectively. Before olfering by slipping $\mathbf{P}$ into its place.* Those who any further remarks upon the subject I shall have not seen this little furnace in operation, briefly describe a simple piece of apparatus, can form no conception of its actual power. which I always make use of at this stage of Mr. E. M. Clarke, of the Strand, has made the analysis, because (as far as $I$ am aware) a number of them for sale, from a specimen it is almost unknown in London. It is a small spirit-furnace, which was introduced into this country, a few years ago, by Dr. Samuel Brown, who met with it at St. Petersburgh.

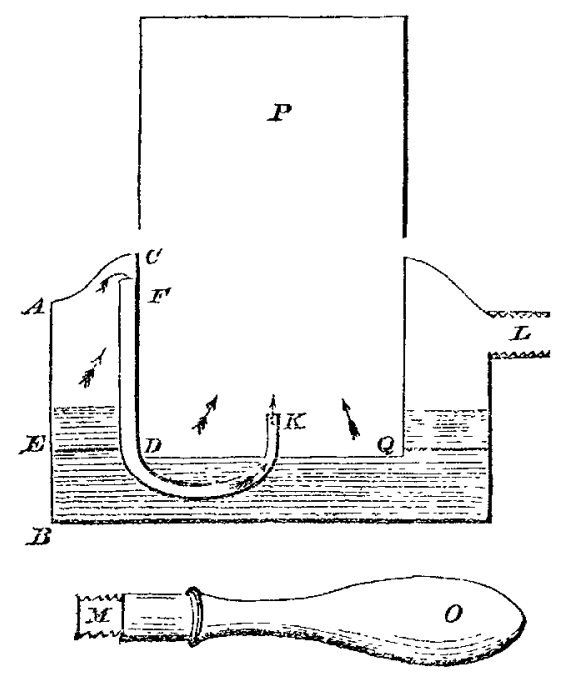

It consists of three principal parts. $\mathbf{A}, \mathbf{B}, \mathbf{C}, \mathbf{L}$; the body of the apparatus is about 3 inches in diameter, and 2.3 inches deep ; it is furnished with a false side, represented in the diagram by $\mathrm{C} D$, and a partial false bottom, $\mathbf{E}$, so fixed as to in. close the space A C D E, which has thus no communication with the inner space, C D E B, except by the bent tube F D K, open at both ends, and tapering to a very small aperture at $K$. The distance between $A E$ and $C D$, and between E $D$ and the bottom is 0.8 inch. $M O$ is a handle, fitting by the male screw $M$, into $L$, which opens into the outer space. The part $P$ forms a cover for the apparatus when not in use, descending into, and closely fitting the open space $\mathbf{C} D \mathbf{D}$, situated below it in the diagram. It also answers the purpose of a measure.

This measure, P, is filled with alcohol, or pyroxylic spirit, and emptied by a small spout (not indicated in the diagram) through $\mathbf{L}$, into the space between the sides, and the handle is screwed in. The same measure of spirit is introduced into the open space C D Q, and kindled. The spirit in the outer space soon warms and boils, and the vapour forced through $\mathbf{F} \mathrm{D} K$, under pressure, rushes throngh the centre of the quiet flame of the spirit in the open inner space $C D Q$, which I placed in his hands, which had been made by Stevenson, of Edinburgh,

With regard to the average quantity of fixed inorganic salts excreted in twenty-fou" hours, Becquerel assigns 150 grains for men, and 130 for women, of adult age and in perfect health. This estimate is, in my opinion, rather too low, and, in fact, Becquerel has allowed himself here (as in numerous other cases) to generalise too hastily. In this instance he places the superior and inferior physiological limits between which (in health) the quantity of inorganic salts must lie, at 10 grammes and 8 grammes respectively, or at 154.4 and 123.3 grains. It is somewhat strange that he should lay down these limits in so arbitrary a manner as he does, since he must have been aware that Iscanu's experiments at once overthrew them.

In eleven of the persons experimented upon by Lecanu, without regard to age or sex, the limits were 378 and 75 grains. In the young man $A$, the maxima and minima of four analyses were 340 and 218 grains; in $C$, they were 314 and 183 grains, as de. duced fiom six analyses.

From Lecanu's experiments it further appears that the quantity of fixed salts is greater in men at an adult age than in women, children, or very aged persons :-

In man, at an adult age,-maximum, 378 grains; minimum, 150 graius; mean, 254 grains.

In woman, at an adult age,-maximum, 295 grains ; minimum, 162 grains; meau, 216 grains.

In children, at about eight years, -maximum, 164 ; minimum, 99 grains ; mean, 151 grains.

In aged persons (eighty-four to eighty-six years),-maximum, 147 grains; minimum, 75 grains; mean, 121 grains.

The objections made to Becquerel's limits of the quantity of fixed salts discharged in twenty-four hours, hold equally good regarding the limits which he assigns for their relative proportion in 1000 parts. These limits he places at 8 and 5.5 ; a reference to the analyses collected in my last paper, or to my own analyses in the present communication, will at once point out their fallacy.

Having thus considered the saline mass generally, as far as its quantity and relative

* Description of a Spirit-farnace, brought from St. Petersburgh, by Samuel M. Brown, M.D., Edinburgh. (London and Edinburgh Monthly Journal of Medical Science. Vol. 1 . Page 419?: 
proportions are concerned, we shall proced to offer a fow remarks upon the variations of each individual portion of it.

a.-The quantity of the earthy phosphates roided in twenty-four hours may vary, according to Lecanu, from 30 to 0.44 grains. Lehmann found that he excreted, when in health, about 17 grains in twenty-four hours. The quantity excreted during this period of time appears to vary as much in the same individual at different periods as between different indivicluals; thus, upon examining this point upon two separate occasions in a woman of twenty-eight ycars of age, in good health and taking moderate exercise, the quantity in one of these analyses was fousd to be 24 grains, aud in the other only 3 grains. The same experiment was tricd upon six occasions upon a healthy man, aged thirty-five, of an athletic form, bilious temperament, and, at the period re. ferred to, confined to the house in conse. quence of a fracture of the clavicle. In this case the limits were 17 and 6.3 grains respectively.!

An opinion was broached, some thirty or forty years ago, by Fourcroy, that the urine of aged persons contained a large proportion of this salt, in consequence of the osseous system being surcharged with earthy phosphates. Recent observation has shorwn the opinion to be utterly devoid of truth. Guibourt, Rayer, Lecanu, \&c., have treated urine passed both by old meu and adults with oxalic acid, and have found that, usually, that of the adults became turbid, whilst the urine of the old men retained its original trausparency.

The proportion of the earthy phosphates in the urine of pregnant women is remarkably diminished, in consequence of that material being required for the formation of fotal bone. The diminution is so well marked as to have led Donué to propose it as a test for pregnancy.

$\beta$. - The quantity of common salt (chloride of sodium) voided in twenty-four hours varied, in Lecanu's experiments, from 116.5 to 0.247 grains. In the same individual the quantity varies at different periods, and is directly influenced by the quantity of salt laken with the food. In A it was found to vary, upon foul different trials, from 116.5 to 67 grains, and in E, in six trials, from 82 to 29 grains. Dr. Pront observes that the quantity of chloride of sodium in the urine diminishes remarkably upon the near approach of death. From my own observations I am led to differ from him upon this point; the dimi. nution in the cases observed by Dr. Prout was probably due to the circumstance of litle or no chloride of sodium having been recenlly taken into the system. I should, perhaps, remark that my objection particularly refers to the urine of persons dying simply of old age. I am perfectly aware that in some diseases, especially in typhus fever and typhoid diseases, the chloride of sodium is found in only very minute quantities in the urine as the disease approaches a final termination.

$\gamma$ - - The quantity of sulphuric acid in the urime of twenty-four hours averages, according to liecquerel, about 17 grains. According to Lelimann's ohservations upon himself it appeared to amount to about 34 grains daily. Lecanu found it to vary from 57.5 to 15.25 graius. Simon* has endeavoured to show that there is a constant relation between the quantities of urea and of sulphu. ric acid; that is to say, that the sulphates and the urea always increase and decrease in the urine sinultaneously.

8.-The quantily of phosphoric acid or the phosphate of soda and ammonia contained in uline voided in twenty-four hours varies, according to Lecanu, from 25.37 to 0.17 grains. Or. Thomson found, in 1000 grains of urine, 1.131 of phosphoric acid, independently of the phosphate of lime. This corresponds with about 12 grains daily. According to Becquerel the whole of the phosphoric acid (including the phosphoric acid of the phosphate of lime) amounts only to 6.3 grains.

Although the value of these observations is perhaps diminished by the want of constancy in the results, they are, at any rate, suflicient to show the fallacy of an opinion expressed by one of our highest authorities that the quantities of sulphuric and phosphoric acids in the urine are very nearly equal.

The quantity of phosphoric acid (in combination with soda and ammonia) is by no means constant in the urine of the same individual. Thus, in the case $A$, of Lecanu, one analysis gave nearly 11 grains, and another not quite 1 grain, of this acid; and in the case $C$, one analysis gave 2 grains and another not quite 2 grains; or, in other words, in one case it was about ten times as abundant as the other.

Lecanu is of opinion that the sulphates and the phosphates of the blood are suficient to account for the small quantity of sulphuric and phosphoric acids daily excre. ted by the urine, without having recourse to the assumption of Berzelius that the sulphur and phosphorus of the albumen, fibrine, \&c., are oxidised by the kidneys. We must reserve the discussion of this question to a future day, and shall conclude the present paper with another reference to the labours of Becquerel. He estimates the quantity

* See Simon's "Anthropochemie," p. 367. The "Anthropochemie," forms the second volume of the "Medizinishen Chemie." An English edition, with copious notes by Dr. Simon, is now in the press, which will contain a much more perfect abstract of the true state of aninual chemistry than any work that has yet appeared in our language. 
of potash excreted daily at 26 grains, and the aggregate of the soda, lime, and mag. nesia, at about 80 grains.

In the present number of the "British and Foreign Medical Review" there is a review of Becquerel's work upon the urine, in which the author has unfortunately mistaken grammes for grains. I venture to notice this error publicly, in order to put the readers of that (otherwise excellent) article upon their guard with respect to the numerical data, which are thus rendered perfectly valueless.

Southwick-street, Hyde-park-square.

\section{CASES OF ACUTE ARACHNITIS OCCURRING IN CHILDREN.}

\section{To the Editor of The Lancet.}

SIR,-I have sent for insertion in THE LANCET, with your permission, a detailed account of two interesting cases of arachnitis occurring in infancy, which I read before the Westminster Medical Society at their last meeting. The first of these cases came under my observation within the last few days, and the other ten years ago. They are the only cases of the kind I have had an opportunity of observing, in a practice of some extent among children, and, in the opinion of several of my medical friends, they are of rare occurrence. I have, therefore, thought their publication would not be altogether devoid of interest to others. Little discussion took place at the Medical Society, still the cases, whether viewed in contrast or considered separately, offer some points of considerable interest; and especially in reference to convulsions. In the second case there were none. The mother of the child assured me he had never had a fit of any kind. Now, what was the pathological condition observed? Effusion of a layer of lymph under the arachnoid upon the whole superficies of the brain, a large effusion of serum into the ventricles, and upon the brain between the membranes, giving rise to a decided tumefaction of the scalp above the anterior fontanelle, and but little or no effusion at the base of the skull. It is here perfectly obvious there had existed no undue pressure upon the medulla oblongata from serous effusion, so abundant between the membranes upon the brain and in the ventricles, and hence the true spinal system was not involved. In the first case, the child had no convulsions until within a few days of his death. Previous to their accession I had been so forcibly impressed with the increasing tumefaction alove the anterior fontanelle, that I seriously entertained the notion of puncturing it. Coutemporaneously with the convulsions, the swelling abated; on the last day of his life it had quite sub. sided, and death was followed by a corresponding depression. Now, what was the pathological condition in this case? I need only allude to the serous effusion. It was found exclusively at the base of the skull, and in the spinal cavity. Here it is manifestly obvious that the medulla oblongata and spinal cord were subjected to undue pressure; the true spinal system was involved, and for the last two days of his life the child was not free from convulsion. I think it is due to Dr. Marshall Hall to say that since his discoveries and exposition of the nervous system, more especially of the true spinal, the cerebral diseases of children have, in my mind, been invested with a new and an in. tense interest.

A rachnitis of the ventricles and basis of the brain is, I believe, considered pcculiar to infancy. In the present case, the drawing backwards of the head was a strongly marked symptom, and proved a true indica. tion of the existence of inflammatory action about the pons varolii; for here there was a thick layem of this lympho-purulent substance. I regret not having had opportunity of seeing this substance under the microscope ; but, on the authority of a competent observer, I may add, the pus corpuscles were more numerous than the lymphatic. In its general appearance and characters it par. took more of the nature of lymph than pus; it appeared to be lymph passing or degenerating into pus. I am, Sir, your obedient servant,

Norfolk-street, Feb. 12, 1844.

Robert Dunn.

Case I.

Acute arachnitis occurring in a child fine months old, in which the interior of the ventricles were found to be filled with a yellow, thick, consistent substance (lympho-purulent), and a layer of which was also found situated between the tunica arachnoides and pia mater, on the anterior convexity of the cerebrum, and at the basis of brain, where the optic nerves decussate, and about the pons varoli.

History.-The child was born a fine, healthy, strong boy, and continued so for the first two months, when Mr. Dunn was called to attend it for an attack of diffused bronchitis, with pneumonia of the left lung. This was on the 11th of November. The attack was a very severe one, and he was obliged to have recourse to leeching, blistering, calomel, and antimony, and saline medicines. To his surprise, after the child had been closely confined to the bedroom for sixteen days, the eruption of measles appeared. At the commencement of the attack the symptoms led to an apprehension of measles or hooping-cough, but he had quite abandoned the expectation of either, when the measles suddenly came on. About the third or fourth day from the attack, a slight eruption had appeared, resembling roseola, but it only remained a few hours. The child 